\title{
The Grave Resolution to the Gamer's Dilemma: an Argument for a Moral Distinction Between Virtual Murder and Virtual Child Molestation
}

\author{
Morgan Luck ${ }^{1}$ iD
}

Received: 29 October 2021 / Revised: 24 November 2021 / Accepted: 15 December 2021 /

Published online: 10 January 2022

(C) The Author(s), under exclusive licence to Springer Nature B.V. 2022

\begin{abstract}
In this paper a new resolution to the gamer's dilemma (a paradox concerning the moral permissibility of virtual wrongdoings) is presented. The first part of the paper is devoted to strictly formulating the dilemma, and the second to establishing its resolution. The proposed resolution, the grave resolution, aims to resolve not only the gamer's dilemma, but also a wider set of analogous paradoxes - which together make up the paradox of treating wrongdoing lightly.
\end{abstract}

Keywords Gamer's dilemma · Computer games · Graveness · Virtual child molestation · Virtual murder

\section{Introduction}

The aim of this paper is to present a new resolution to the gamer's dilemma (Luck, 2009a). This is done by first formulating the dilemma as a paradox and then identifying its scope. A set of analogous dilemmas are then introduced to suggest that the gamer's dilemma is actually an instance of a more general paradox: the paradox of treating wrongdoing lightly. If true, a resolution to this new paradox will also constitute a resolution the gamer's dilemma. To this end a resolution to this new paradox is proposed: the grave resolution. We begin with the formulation (and then reformulation) of the gamer's dilemma.

Morgan Luck

moluck@csu.edu.au

1 School of Social Work and Humanities, Charles Sturt University, Bathurst, Australia 


\section{What Is the Gamer's Dilemma?}

The gamer's dilemma is a puzzle concerning the moral permissibility (henceforth permissibility) of two acts we might perform, typically when playing computer games.

The first act is virtual murder. Broadly speaking, virtual murder occurs when one character murder's another in a virtual environment, such as a computer game. However, the focus here is on instances where players are involved. In particular, where players intentionally cause their character to murder another in a computer game. An example of this would be a player directing their character to drive over an innocent pedestrian - killing them - in the game GTA 5 (in circumstances such, were the game world actual, it would constitute actual murder). ${ }^{1}$ For the sake of simplicity we shall limit our discussion to instances where the character being murdered is a nonplayer character (or NPC).

Many consider virtual murder permissible. ${ }^{2}$ This is often on the grounds that no one is actually murdered - it is just a game. ${ }^{3}$ However, this defence also seems to apply to a second type of act: virtual child molestation (also referred to as virtual paedophilia).

Broadly speaking, virtual child molestation occurs when an adult character molests a child character in a virtual environment, such as a computer game. However, we again focus on instances where players are involved. In particular, where players intentionally cause their adult character to molest a child character in a computer game. An example of this would be someone playing a 40 year-old man driving up to a young boy in a GTA style game, luring them into his car and groping them (in circumstances such, were the game world actual, this would constitute actual child molestation). Again, for the sake of simplicity we shall limit our discussion to instances where the character being molested is a NPC.

Many consider virtual child molestation to be impermissible. ${ }^{4}$ However, it is hard to see what the relevant difference is between virtual murder and virtual child molestation. Why? Because defences of virtual murder (such as the just a game defence) also seem applicable to virtual child molestation (for no one is actually murdered or molested in such games). But if the two acts are analogous, and virtual murder is permissible, then the following argument can be made for the permissibility of virtual child molestation:

\footnotetext{
${ }^{1}$ It is worth noting that Heinrichs (2020) believes that this type of analogy (between an actual wrongdoing and it's virtual counterpart) "while occasionally resulting in correct results by chance-leads to absurd results when applied across the board" (p.2).

2 Although Ali (2015), Nader (2020) and Flattery (2021) all give reason to think that certain instances of virtual murder are always impermissible. And Tilson (2018) provides reason to think all instances of virtual/simulated murder are, to some extent, wrong.

3 The 'just a game' defence is also sometime known as the 'magic circle' defence. For a great overview of this defence see Nguyen (2017).

4 Although Ali (2015) gives us reason to think that certain instances of virtual child molestation may be permissible.
} 
1. Virtual murder is permissible.

2. There is no relevant difference between virtual murder and virtual child molestation, in respect to being permissible.

So,

3. Virtual child molestation is permissible ${ }^{5}$

This argument serves as a good introduction to the gamer's dilemma. It shows that if we want to reject 3 , then we must show that 1 is false, or 2 is false, or that the argument is invalid. Why is this a problem? Because 1 and 2 are plausible (or at least they are not implausible) and the argument seems valid.

The dilemma can also be presented as a paradox, by removing the inference and changing the permissibility of virtual child molestation in 3 , as follows:

1. Virtual murder is permissible.

2. There is no relevant difference between virtual murder and virtual child molestation, in respect to being permissible.

3. Virtual child molestation is impermissible.

I have a slight preference for this presentation of the gamer's dilemma. This is because it can be easier to critically regard the truth of each of these propositions when they are not presented in a way that suggests one of them is "an apparently unacceptable conclusion derived by apparently acceptable reasoning from apparently acceptable premises" (Sainsbury, 2009, p.1). So we shall continue with this paradox in mind. To resolve this dilemma (or, more precisely, trilemma) we must either show that, at least one of the propositions is false, or that the set is not inconsistent. $^{6}$

Many proposed resolutions to the dilemma seek to demonstrate that 2 is false ${ }^{7}$; that is, they argue that there is a 'relevant difference' between virtual murder and virtual child molestation (in respect to their permissibility). However, clearly demonstrating something constitutes a relevant difference isn't as straightforward as it might initially seem. So, to help us to better evaluate such resolutions, let us next consider exactly what constitutes a relevant difference.

\footnotetext{
5 This formulation was originally given by Luck (2017, 2018, p.157), and has also been followed by Tilson (2018, p.208), Bartel (2020, p.122), Nader (2020, p.239), and Öhman (2020, p.139).

${ }^{6}$ Another option is to attempt to dissolve (as opposed to resolve) the dilemma, by that showing that at least one of the propositions is actually implausible. In which case the dilemma fails to get off the ground. Ali (2015) and Ramirez (2020) provide excellent examples of this approach.

${ }^{7}$ For example, Bartel (2012), Young (2016), Kjeldgaard-Christiansen (2020), and Milne and Ivankovic (2021).
} 


\section{What Is a Relevant Difference?}

To illustrate the notion of a relevant difference let us examine an argument provided by Bartel (2012). Bartel seeks to establish a relevant difference between virtual murder and virtual child molestation, and so demonstrate the falsity of 2. Let's use this example to better understand what relevant differences are and how they work.

Bartel asserts that "there is a relevant moral distinction to draw between virtual murder and virtual paedophilia that is able to justify the former but not the latter" (11), and that if his argument stands "then we can take the gamer's dilemma to have been resolved." (16). In other words, he is attempting to resolve the dilemma by showing that 2 is false. ${ }^{8}$ Bartel does this by arguing that virtual child molestation is pornographic, and pornography sexualises inequality. ${ }^{9}$ In which case, as sexualising inequality harms women, such acts are impermissible.

Bartel's argument against 2 can be expressed as follows:

4. Virtual child molestation sexualises inequality and virtual murder does not.

5. If an act sexualises inequality then it is impermissible.

So,

6. There is a relevant difference between virtual murder and virtual child molestation, in respect to being permissible

And if 6 is true, 2 will be false - and so the dilemma is resolved.

I think Bartel's argument is valid. ${ }^{10}$ However, it's validity might not be obvious. To make its validity clear let us consider exactly what a relevant different is.

A relevant difference between two actions, in respect to permissibility, is a difference in their properties - such that one action possesses a property necessary for permissibility, but the other one lacks this property. (This difference would explain why one action is possibly permissible, but not the other.) This proposal can be formulated as follows:

If $\mathrm{A}$ has some property that $\mathrm{B}$ lacks and something is a $\mathrm{C}$ only if it has this property, then there is a relevant difference between $\mathrm{A}$ and $\mathrm{B}$ in respect to being a $\mathrm{C}$.

\footnotetext{
${ }^{8}$ It has been argued elsewhere (Luck \& Ellerby, 2013) that Bartel might only intend to provide an explanation of virtual child molestation's impermissibility that does not apply to virtual murder (which would not resolve the dilemma), rather than an argument for a relevant difference between them (which would). For our purposes, we will put this possibility aside.

${ }^{9}$ Note that, like Bartel, I think the sexualisation of inequality may be playing an important role. For it is also an instance of oppression, which may help to explain why some wrongdoings are graver than others. I flesh this out in Section 7.0.

${ }^{10}$ Although perhaps not sound. Luck and Ellerby (2013) provide reason to question the truth of premise 4; as not all instances of virtual child molestation are pornographic (e.g. an instance of molestation that is initiated by the player, but not depicted - imagine the screen fades to black after a player initiates the act then the game picks up in such a way that we a clear about what has just occurred).
} 
In other words, a relevant difference in respect to being a $\mathrm{C}$, is a property that one thing has but the other lacks, which is necessary, but not necessarily sufficient, for being a $\mathrm{C}$. At least two questions arise from this formulation.

First, why is this property necessary for being a C? Let us return to Bartel's resolution to help explain this. Bartel holds that sexualizing inequality is a relevant difference between virtual murder and virtual child molestation. Which, on this formulation means if something sexualizes inequality then it is impermissible. Or, put another way, if an act is permissible then it doesn't sexualize inequality. Or, put more awkwardly, a necessary property of something being permissible is it not sexualizing inequality. To help us understand why this property is necessary, let us imagine for a moment that it wasn't. This opens the possibility that something might sexualize inequality and yet still be permissible. Which in turn would make it possible for both virtual murder and virtual child molestation to be permissible. Which is not the intended outcome of establishing a relevant difference. So, the property we use to establish a relevant difference must be one which is necessary (but not necessarily sufficient) for being a C.

Second, why is this property not necessarily sufficient for being a C? Let us again return to Bartel to help explain this. Bartel holds that if something is permissible then it doesn't sexualize inequality. However, it doesn't follow from this that anything that doesn't sexualize inequality is permissible. Insider trading, for example, doesn't sexualize inequality, but that doesn't mean it is permissible. This is why, although the property in question is necessary for being a $\mathrm{C}$ (in this case, for being a permissible act), it doesn't follow that it is sufficient for being a $\mathrm{C}$.

So, in the case of Bartel's resolution, we can recognize that there is a relevant difference between virtual child molestation and virtual murder (in respect to being permissible) if virtual murder doesn't sexualize inequality, but virtual child molestation does. For anything which does sexualize inequality is impermissible, and for anything to be possibly permissible it must not sexualize inequality. Given this understanding of a relevant difference, Bartel's argument is valid.

What does this mean for the formulation of the gamer's dilemma? It means that one way to show 2 is false, is to show that virtual murder has a property necessary for permissibility that virtual child molestation lacks. Which would show that virtual murder is possibly permissible, whereas virtual child molestation is not - which would be a relevant difference. So, to help focus challenges to 2 it might help us to reformulate 2 as follows:

2. It is not the case that, virtual murder has some property that virtual child molestation lacks, where such acts are permissible only if they have this property

With 2 reformulated like this the gamer's dilemma should now be a little clearer. And this clarity will help us later on to evaluate a new resolution: the grave resolution. A resolution which also attempts to establish a relevant difference (i.e. suggest 2 is false). However, we can make things clearer still by now turning our attention to the limits (or scope) of the dilemma. 


\section{Does the Dilemma Hold in all Cases?}

The force of the dilemma is determined, in part, by whether it holds for all cases of virtual murder and virtual child molestation, or just some of them. In this section, reason will be given to limit the dilemma to only some cases. Why argue for the scope of the dilemma to be limited? Because it makes the dilemma more defensible. However, limiting the dilemma's scope to the right set of cases is (as we shall see) difficult. ${ }^{11}$ As we are caught between reason to maximize the dilemma's reach (and thus a resolution's explanatory strength), and reason to minimize its reach (to make it more defensible). To introduce this issue let us consider Ali's attack on the dilemma without any limits.

Ali argues that "it is neither the case that all acts of virtual murder are acceptable, nor that all acts of virtual pedophilia are unacceptable"(p.268). To illustrate this point, consider the following game-classification case:

Bob works for a government classification board. One of his duties is to play new computer games and recommend appropriate ratings. Because (and only because) it is his duty to play such games he performs the act of virtual child molestation.

In this case, Bob seems to be doing something permissible (he is attempting to familiarize himself with the contents of the game in order to recommend an appropriate rating). And if Bob is acting permissibly, the following argument could be mounted:

7. Virtual child molestation in the game-classification case is permissible

So,

8. Not all cases of virtual child molestation are impermissible

This argument seems to show that proposition 3 of the dilemma is false:

3. Virtual child molestation is impermissible

A result which would resolve the dilemma.

However, because 3 is expressed as a generic claim it is not clear whether this argument does actually resolve the dilemma. The argument would clearly show 3 to be false if 3 were expressed as a universal claim:

3. All cases of virtual child molestation are impermissible

Which in turn would call for the following reformulation of the dilemma:

1. All cases of virtual murder are permissible.

\footnotetext{
11 If Ali (2015) and Nader (2020) are correct, then this difficulty may be explained by the fact that there is no dilemma to limit. For they argue when comparing virtual wrongdoings of similar games types the dilemma dissolves. So (putting aside the possibility that the dilemma might hold when comparing wrongdoings in different games types) the edges of the dilemma might not be there to be found.
} 
2. It is not the case that, all cases of virtual murder have some property that all cases of virtual child molestation lack, where such acts are permissible only if they have this property.

3. All cases of virtual child molestation are impermissible.

Let us call this the unlimited formulation of the dilemma. Because of counterexamples such as the game-classification case, the unlimited formulation seems too weak to defend. So, the dilemma should be limited to avoid such cases. And some, such as Ali (2015) and Bartel (2012), have attempted to do just this. Let us consider next these two proposed limitations.

Ali suggests that the dilemma be limited to those cases where the "gamer lets her context be dictated by the in-game context" (p.270), ${ }^{12}$ that is, where players play the game (by and large) as the designers intend. ${ }^{13}$ In a different vein, Bartel believes that the dilemma should be limited to cases where the acts are depicted on-screen (p.15). If limitations such as these two were in place, the dilemma would have the following schema:

1. $\mathrm{X}$ cases of virtual murder are permissible.

2. It is not the case that, $X$ cases of virtual murder have some property that $Y$ cases of virtual child molestation lack, where such acts are permissible only if they have this property.

3. Y cases of virtual child molestation are impermissible.

In this schema, $\mathrm{X}$ and $\mathrm{Y}$ refer to the types of cases to which we should limit the dilemma ( $\mathrm{X}$ and $\mathrm{Y}$ might be the same set of cases). This way of thinking about the dilemma strengthens it insofar as it limits the range of possible counterexamples it is exposed to under the unlimited formulation (such as the game-classification case). This seems like the right way to think about the dilemma - and we shall continue with this schema in mind. However, we leave open what $\mathrm{X}$ and $\mathrm{Y}$ are. Why? Because, as we shall see next, getting $X$ and $Y$ right is difficult (and, as I will argue, we might not need to pin them down).

When limiting the dilemma, we should be wary of omitting cases where the propositions of the dilemma are plausible (that is, seem to be true, or at least not obviously false). For example, if we were to follow Ali, and limit the dilemma to cases

\footnotetext{
12 Ali argues that when virtual wrongdoings have similar in-game contexts, the permissibility of these acts will also be similar. For example, if virtual murder and virtual child molestation both occur within the a storytelling game where "neither the representations nor the viewpoint of the game are objectionable"(p.271), then both acts will be permissible. Likewise, if these virtual acts both occur in simulations, then both acts will be impermissible. This leads to the conclusion that, when the acts being compared occur in the same context there is no dilemma. In other words, when comparing similarly positioned acts, if 1 is true then 3 will be false (and vice versa).

13 By limiting the gamer's context this way Ali (2015) attempts to saves the dilemma from becoming trivial. For without it he argues the "morality of virtual acts will turn on whether the gamer engages with these acts in a morally perverse manner or not, and not on the type of act performed (p.269).
} 
where players play the game as the designers intend, then we would be omitting the following case:

Imagine a game like GTA 5 that allows players to virtually murder. However, unlike GTA 5, it also allows players to virtually molest children. The game's designers intend players to follow the game's storyline whilst also enjoying simulating various activities (like driving tanks, skydiving, etc.). Now consider two similar players: Andy and Ben. Both play the game in a manner not intended by the designers - that is, they play in a specifically competitive way - both are trying to see who can cause more virtual harm than the other. Andy does this by running over innocent pedestrians, but refuses to virtually molest children. Whereas Ben has no such qualms and proceeds to virtually molest children.

If it is plausible that Andy's actions are permissible, whilst Ben's are not, and it is not obvious what the relevant difference is between their actions, then this case still seems like an instance of the gamer's dilemma. ${ }^{14}$ However, if we limit the dilemma to cases where players are playing the game the way their designers intend then this case will fall outside its scope.

The same point can be made in relation to Bartel's limitation, where the dilemma is limited to cases where the virtual acts are depicted on screen. Consider the following case:

Imagine a game like GTA 5 that allows players to virtually murder. However, unlike GTA 5, it also allows players to virtually molest children. However, in this game these two acts are not depicted. Rather, the screen fades to black during these acts and the game continues on afterwards, with either a dead body lying at the player's feet, or a crying child. Now consider two similar players: Andy and Ben. Both play the game the same way. However, although Andy virtually murders people, he refuses to virtually molest children. Whereas Ben has no such qualms and proceeds to virtually murder and molest.

If it is plausible that Andy's actions are permissible, whilst Ben's are not, and it is not obvious what the relevant difference is between their actions, then this case still seems like an instance of the gamer's dilemma. However, if we limit the dilemma to cases where the acts are depicted, then this case will also fall outside its scope.

\footnotetext{
14 Nader (2020) doubts such a case could be an instance of the gamer's dilemma; for "in competitive games where the players are murdering/molesting non-participants in the competition, both virtual murder and virtual child molestation are intuitively impermissible since the rules do not override our intuition"; as opposed to, for example, boxing matches - where the rules of the competition override our intuition that hitting someone is wrong, as "it is permissible to hit your opponent within a boxing match... because by entering into the ring they consent to it" (Luck, p.282). However, there are plenty of instances where murdering NPCs have occurred in competitive games with few complaints. For example, for many years one could murder innocent hostages in Counter-Strike (until the hostages were made invulnerable in later versions), and in Rampage (a competitive game in which you play a monster) you are rewarded for murdering humans. Both games were hugely successful. However, their success would probably been curtailed somewhat were they to feature the rape of children, rather than the murder of adults.
} 
Note that I am not suggesting that the dilemma should not be limited (it should be); only that there are dangers in doing so. Ideally what we want is a way of limiting the cases to only those where the dilemma seems at large. Of course, we can do this explicitly as follows:

$\mathrm{X}$ and $\mathrm{Y}$ are those cases where the propositions of the dilemma seem plausible, and the set seems inconsistent.

However, this isn't too helpful. Yet, we should be looking for a limitation like this one, insofar as it maximizes the dilemma's reach. What we want is for $\mathrm{X}$ and $\mathrm{Y}$ to limit the cases to those where each proposition of the dilemma is plausible, and the set seems inconsistent - and so excludes cases like the game-classification case, whilst including as many cases as possible where the dilemma holds.

Why look for a limitation that maximizes the dilemma reach? Because, if we are aiming for a single resolution (that is, one resolution for every instance of the dilemma), only such a limitation will suit. And why look for a single resolution? Because, unless we have reason to do otherwise, we should try to maximize explanatory strength. That is, we want as few resolutions as possible to resolve as many instances of the dilemma as possible.

Note that I'm not suggesting a single resolution exists, or that there are not multiple possible resolutions that we could employ to resolve different instances of the dilemma. Only that we should aim for a single complete resolution... at least until we know better.

The purpose of this section was to confirm that the dilemma should be limited, and indicate why pinning these limits down is difficult; for we are caught between reason to maximize the dilemma's reach (to reduce the need to produce alternative resolutions to closely related dilemmas), and reason to minimize the dilemma's reach (to make it more defensible by baring certain possible counterexamples). So how should we proceed?

Without knowing the exact limits of the dilemma, one way to proceed is to look for a resolution that has a very wide scope. Consider this following analogy: even if you don't know which room in your house the termites have built their nest, you still might be assured that treating the whole house with pesticide will resolve the problem. Similarly, maybe we are able to offer a resolution to the gamer's dilemma without knowing its exact limits, providing that the resolution's scope is wide enough. It is in this vein that we proceed.

In the next section we will consider a set of dilemmas which contains the gamer's dilemma and others of a similar kind. With this set in mind a new paradox will be presented: the paradox of treating wrongdoing lightly. To employ the termite analogy again: just as the house contains the termite infested room, this new paradox contains the gamer's dilemma. And, just as treating the whole house treats the infested room, resolving this new paradox should also resolve the gamer's dilemma. 


\section{What Is the Paradox of Treating Wrongdoing Lightly?}

Our aim now is to consider a new paradox - the paradox of treating wrongdoing lightly. This paradox encompasses not only the gamer's dilemma, but also those dilemmas with the same form and content. The purpose of establishing this new paradox is to develop what Davnall (2020) might refer to as a deflationary resolution, where "the gamer's dilemma just as an instance of a more general problem" (p.2). In order to introduce this new paradox, let us begin by considering a real, and very English, television show, Midsomer Murders.

Midsomer Murders is a murder mystery show set in the fictional picturesque English county of Midsomer. Each episode centres on Detective Chief Inspector Barnaby's attempts to solve a murder. The show has a light-hearted, quaint, and often comedic tone (for example, in one episode someone is "amusingly" murdered by a cheese wheel). What has this got to do with the gamer's dilemma? It is relevant because there may be an analogous dilemma lurking in Midsomer. To see this, imagine a bold new spin-off to Midsomer Murders - Midsomer Molestations.

Midsomer Molestations is similar to Midsomer Murders in every respect save one. Rather than solving a murder case in a light comedic manner, Midsomer Molestations involves solving a child molestation case in a light comedic manner. ${ }^{15}$ If viewers of Midsomer Murders were to feel that there would be something wrong with viewing Midsummer Molestations, they would now be faced with what we might call the Midsomer dilemma:

1. X cases of viewing Midsomer Murders are permissible.

2. It is not the case that, $X$ cases of viewing Midsomer Murders have some property that $\mathrm{Y}$ cases of viewing Midsomer Molestations lack, where such acts are permissible only if they have this property.

3. Y cases of viewing Midsomer Molestations are impermissible.

Why is this pertinent? Because the Midsomer dilemma and the gamer's dilemma seem quite similar. They have the same structure and very similar (but not identical) content. Given their similarity, it would not be surprising to discover that they both had the same resolution. This might suggest we look for resolutions that appeal to the shared features of both dilemmas. Which would mean that a potential resolution to the gamer's dilemma that relies on, for example, the active nature of computer games, would not suit; as it wouldn't be applicable to the Midsomer dilemma (since consuming fictional content on T.V. is typically a passive activity). ${ }^{16}$ So, such

\footnotetext{
15 This is not to suggest that all forms of entertainment that treat child molestation in a comedic way will be intuitively impermissible. For example, transgressive comedies such as It's Always Sunny in Philadelphia and The Family Guy routinely treat child molestation in such a way. However, the context of such shows (be it their satirical nature, or some other feature), seems to eliminate, or at least obfuscate, our normal intuitions regarding the graveness of such matters. However, such features are in limited supply in Midsomer.

16 This is not to say that the active nature of games is irrelevant; it just can't be a necessary property of the resolution (if the resolution is to apply to the wider set). But this still allows for the active nature of games to play a key role in an indirect way (for a subset of the dilemmas). For if we discover that all
} 
a resolution would not be able to address both dilemmas. Which would suggest that we are barking up the wrong tree by pursuing this line, if both dilemmas have the same resolution.

Of course, there are plenty of other examples of this type of dilemma. For example, why is it that some people are happy to attend murder mystery dinners (where actors play out a murder over dinner and participants look for clues to catch the culprit), but presumably these same people would be less happy to attend a molestation mystery dinner. Why it is that we are happy to knowingly sing merrily along to The Beatles song "Maxwell's Silver Hammer" (which is about a serial killer bludgeoning various people to death), but would be warier of singing merrily along to a song cheerfully describing the exploits of a child molester? ${ }^{17}$ If our intuitions across these examples are all turning on the same relevant difference, then this would suggest the heart of the dilemma does not lie solely in computer game ethics.

In seeking the heart of the dilemma, we might start by asking what is common to the above cases. Each involves an a fictional wrongdoing. ${ }^{18}$ That is, a representation of a wrongdoing. And these fictional wrongdoings occur in modes of entertainment (such as computer games, upbeat pop songs, dinner games, and a light-hearted T.V show). Perhaps this is important. Maybe we should not be engaging with some fictional wrongdoings, like child molestation, in such modes (at least not in some

\section{Footnote 16 (continued)}

fictional wrongdoings that have property A are impermissible, and one way for a fictional wrongdoing to have this property is for gamers to act in a certain way, then their activity is will be salient (insofar as it relates to property A). But this can't be the only way for a fictional wrongdoings to have property A (otherwise property A couldn't be used to resolve the wider set of dilemmas).

17 A further example of this shift in thinking is presented by Kieran (2006) regarding the French movie Man Bites Dog. This movie is about Ben, a serial killer who is portrayed as both "funny and charming, talking about having to do [i.e. kill] a postman on the first day of every month and the difficulties involved in getting rid of dead bodies (especially midgets)" (p.138). However, although cinema audiences found Ben's murderous exploits funny, the mood changes abruptly; as Kieran reports, "everyone laughed up until the central [rape] scene and from then on the atmosphere was deadly quiet" (p.138). This shift in intuitions is also reflected in an experiment by Sabo and Giner-Sorolla (2017). They conclude,

...that one may be given a pass for enjoying violent video games and films, or having aggressive thoughts towards another individual. Consequently, these fantasies may be seen as relatively benign and nonconsequential. When the fictional acts, however, involve a bizarre and socially unacceptable use of the body, they are not granted the same pass that is given to fictional social harm. Not only do these acts signal a poor character, they are seen as a cause of future indiscretions. As it turns out, not all fiction is treated equally and, while it is all make-believe, impure fiction is associated with very real consequences. (p.152)

18 Care must be taken here, as the term 'fictional wrongdoing' might be understood in different ways. Consider the Shakespearean play Julius Caesar. Upon witnessing the murder of Caesar during a production of this play you might whisper to your friend "This isn't fiction, it actually happened in 44 B.C.E!"; in this sense the murder is not fictional. However, your friend responds "This is a play. No one has actually been murdered"; in this sense the murder is fictional. It is the latter sense that it intended here. The term fictional wrongdoing has also been adopted by Mildenberger (2017) and Tilson (2018) in this context. It might also be worth quickly considering the distinction between virtual and fictional wrongdoings. The term 'virtual wrongdoing' typically refer to wrongdoings that are represented in computer games (or digital worlds). Whereas the term 'fictional wrongdoing' refers here to a representation of a wrongdoing. So, whilst all virtual wrongdoings are fictional wrongdoings, not all fictional wrongdoings are virtual (for example, a murder in a T.V. drama is a fictional murder, but not a virtual murder). 
cases). Why not? Perhaps it is because in doing so we are treating these fictional wrongdoings, and by extension the actual wrongdoings to which they relate, too lightly.

What does it mean to treat something lightly? For our purposes we can think of it as acting with an insouciant, carefree or light-hearted attitude towards something; the attitude one typically holds when playing a computer game like GTA 5, or watching a TV show like Midsomer Murders. And why is it impermissible to sometimes treat things lightly? Maybe because it can be disrespectful, ignorant, insensitive, cavalier, or offensive etc. For our present purposes we need only suggest it is plausible that it is sometimes impermissible to treat things lightly. We leave unanswered, for now, the question as to why this might be the case. To better understand the notion of treating something lightly, it is worth comparing it to two related notions also brought up in the context of the gamer's dilemma: Seddon's playfulness (2013) and Young's poor taste (2019).

One example of treating something lightly is playful engagement, as identified by Seddon (2013). When someone playfully engages with, for example, a computer game they treat it lightly. However, as Seddon notes, not all people that 'play' do so playfully. For example, a professional e-sports gamer might play a computer game with a serious attitude (p.4). ${ }^{19}$ This point also applies to treating things lightly. As not everyone partaking in something that is typically treated lightly (like a romcom) may be treating it this way. For example, a film critic watching a rom-com may watch it with a very serious attitude. It is also worth noting that, although playfully engaging with something may be an instance of treating something lightly, not all instances of treating something lightly will be playful. For example, a person might treat an issue lightly by not giving it much thought, or treat a custom lightly by barely adhering to it. In such cases, the person holds a carefree or light-hearted attitude towards the issue or custom, without playfully engaging with it.

A second example of treating things lightly are instances of poor taste, as identified by Young (2019). Where an action "is said to be in poor taste if it is believed to trivialize something one considers to be immoral"(p.467). For example, treating the Holocaust lightly by making a crude joke about it might be an instance of poor taste (if it is believed the joke trivialises the Holocaust and the Holocaust is judged as immoral). But not all cases of treating something lightly will be instances of poor taste. For example, I might treat an $\mathrm{OH} \& \mathrm{~S}$ presentation lightly by not listening to it, but this isn't obviously an instance of poor taste (in Young's sense or a general sense). Also treating something lightly may not be dependent on the beliefs and judgements Young identifies. For example, one might treat the Holocaust lightly by making a crude joke about it, even if no one holds a trivializing belief about the joke, or judges the Holocaust to be immoral. That is, the possibility remains that one might treat something lightly, even if nobody thinks so (for people - even all of them - can be wrong).

\footnotetext{
19 Interestingly, although a professional gamer may not be treating a first person shooter game lightly when they 'play' it, it may still be possible for them to treat the representations of violence contained within the game lightly (by, for example, being unconcerned with what they might represent).
} 
So, there are interesting connections between playfulness, poor taste and treating things lightly. And noticing these connections will help us to avoid conflating these overlapping categories, and focus more squarely on the relevant cases; cases where wrongdoings are treated lightly by engaging with their representations in a carefree or light-hearted manner. It is these cases which are the fodder of the paradox of treating wrongdoing lightly.

If it is plausible that it is sometimes wrong to treat fictional wrongdoings lightly, then the paradox of treating wrongdoing lightly might be expressed as follows:

1. X cases of treating fictional murder lightly are permissible.

2. It is not the case that, $X$ cases of treating fictional murder lightly have some property that $\mathrm{Y}$ cases of treating fictional child molestation lightly lack, where such acts are permissible only if they have this property.

3. Y cases of treating fictional child molestation lightly are impermissible.

But perhaps this does not go far enough. Why? Because the same type of dilemma seems to appear if we exchange murder and child molestation with other wrongdoings.

Within some computer games, such as The Sims, players can trap innocent characters in door-less bare rooms for simulated years, in circumstances such, were the game world actual, it would be false imprisonment of a most tortuous kind. Yet we hardly blink an eye. However, if a game were introduced which enabled players to direct their Viking hordes to rape the women of a village, we would be less dismissive.

Within some computer games, such as Skyrim, players can take very valuable items from innocent characters in circumstances such, were the game world actual, it would be stealing of a particularly egregious kind. Again, few eyes blink. However, if a game were introduced that enabled players to shout homophobic insults at gay characters, we would be less dismissive. So, what do these examples tell us about the paradox?

That other types of actions may be able to stand in for virtual murder and virtual child molestation tells us that the heart of the paradox may be wider still. To better determine its width, let us now focus on these wrongdoings.

There are two groups of wrongdoings to consider. First, there are those wrongdoings, such as murder, false imprisonment and stealing, that seem permissible to treat lightly (at least in some cases - X cases). Let's call this first group fair-game wrongdoings. Second, there are those wrongdoings, such as child molestation, rape, and homophobic abuse, that seem impermissible to treat lightly (in some cases - Y cases). Let's call this second group off-limits wrongdoings. With this distinction between fair-game and off-limits wrongdoings in place we can now broaden the paradox to:

1. Treating fair-game wrongdoings lightly is permissible. 
2. It is not the case that, fair-game wrongdoings have some property off-limits wrongdoings lack, where treating such wrongdoings lightly is permissible only if they have this property.

3. Treating off-limits wrongdoings lightly is impermissible.

Understood this way, the paradox no longer applies merely to the playing of computer games, or to cases of fictional murder and fictional child molestation. Its reach is now far wider. (In fact, although we are focusing here on cases where wrongdoings are treated lightly by engaging with their representations in a carefree or lighthearted manner, I imagine the paradox may apply more broadly still. $)^{20}$

The aim of this section was to establish the paradox of treating wrongdoing lightly. Why do this? Because if we can resolve this paradox, we also resolve the gamer's dilemma and other analogous paradoxes. ${ }^{21}$ To illustrate this, let us now consider a potential resolution to the paradox: the grave resolution.

\section{What Is the Grave Resolution?}

Before introducing the grave resolution, it may help to provide an indication of what is meant here by graveness (for this property will play a central role). Graveness refers here to something like seriousness or solemnity. For example, Covid19 is very grave, as it's spread has resulted in the deaths of over a million people; this loss of life being both serious and solemn. Whereas, a red traffic light luckily turning green just before you were about to stop your car isn't grave; such an occasion is neither serious nor solemn. One thing to stress is that graveness is here intended to be an objective property. That is, it is not determined (at least not completely) by what people think is serious or solemn. For example, the Holocaust is both serious and solemn, regardless of whether people regard it as thus. Note that this is not an attempt to give an account of graveness; it is merely an indication of what is intended here (and the resolution itself may be compatible with alternative understandings.)

\footnotetext{
${ }^{20}$ For example, imagine an case where a detective guffaws at a murder report (perhaps because the victim had a funny name), and then later guffaws at a child molestation report (perhaps for the same reason). If we were to judge the earlier guffaw permissible but not the later, but we can't easily point to a relevant difference, then our puzzlement might also be captured by this paradox. In other words, the paradox doesn't require fictional wrongdoings to take center stage (as the murders in this case are actual).

${ }^{21}$ It is worth noting two concerns with this approach. That, by establishing a single paradox that encompasses the wider set of analogous paradoxes, we might: (a) make it harder for people to see that these paradoxes, although related, may be distinct and should be dealt with accordingly; and (b) if a resolution is found, it may only offer a resolution by appealing to the most general property shared by the analogous paradoxes. In regard to point (a), this is valid concern with all ethical justifications that are proposed to be far reaching. For example, one of the strengths of utilitarianism is that can apply to all ethical decisions. However, if moral particularism is true then, utilitarianism will similarly obscure the truth. In regard to (b), were a resolution to apply only by virtue of the most general property shared by the analogous paradoxes, then the resolution will be simple (by virtue of turning on a single property), and strong (by virtue of being applicable to all the paradoxes). And whether it is worth sacrificing simplicity in order to gain further strength will be a question worth considering when comparing potential resolutions.
} 
Our focus is the graveness of wrongdoings. A key point to note about the graveness of a wrongdoing is, that it is sensitive to both extrinsic and intrinsic factors. This point is related to one made by Öhman (2020), who stated that "the permissibility of some actions appears to depend on the degree to which they are abstracted from their natural context" (p.133). So, two wrongdoings that might seem equally grave in abstraction (their intrinsic graveness), might not seem equally grave once we also consider other factors (their extrinsic graveness) - such as: the social context of the wrongdoing; how long ago the wrongdoing occurred; how distanced from reality a fictional wrongdoing may be; and who committed the wrongdoing (and there is bound to be further such factors.) Let's examine each of these factors next.

Let us begin with the social context of a wrongdoing. Öhman (2020) rightly states that,

...it seems that a proper ethical analysis of the gamer's dilemma would also require a full analysis of the social systems in which the actions-virtual murder and virtual paedophilia - take place. (p.139)

Patridge $(2013)^{22}$ also championed this factor, arguing that some wrongdoings are "egregious, long-term, systematic denials of justice that are of a particular kind: oppression" (p.310). Rape, molestation and homophobic insults are examples of such oppressive wrongdoings. For, not only is there a long history of these wrongdoings being disproportionately suffered by disempowered groups (such as women, gay people, and children), they also constitute the cruel and/or unjust treatment of the disempowered by the empowered. The point to highlight here is that some wrongdoings (such as rape) can also be instances of other wrongdoings (such as oppression).

As some wrongdoings are also instances of other wrongdoings, they may be graver as a result. For example, although rape is intrinsically an extremely grave act (that is, by its nature, extremely serious), because of extrinsic and contingent factors, such as the role it has played, and continues to play in the oppression of women, it is graver still. If this is correct, then other off-limits wrongdoings, such as homophobic abuse and child molestation, may also be graver in the same way, since they too are instances of oppression.

Can the same be said of our examples of fair-game wrongdoings (murder, stealing, and false imprisonment)? They do not seem, at least not to the same extent (or perhaps in the same way), to be instances of other wrongdoings on par with graveness of systematic and long-standing oppression.

\footnotetext{
22 In fact, the grave resolution is very much inspired by Patridge's incorrigible social meaning account (2013). Both propose that certain contingent facts about wrongdoings may require that they be taken more seriously, and both have a wider scope - applying to more than just cases of virtual wrongdoing. However, whilst Partridge focuses on people enjoying fictional wrongdoings, the grave resolution focuses on people treating wrongdoings lightly (where enjoying something might be one way to treat it lightly, but not the only way). Similarly, Patridge focuses on fictional wrongdoings that have "an incorrigible social meaning that targets groups of individuals... and minorities"(304), whilst the grave resolution focuses on the graveness of a wrongdoing (where the targeting a minority might be one way for a wrongdoing to be graver, but not the only way).
} 
One might argue against this last point, perhaps by pointing out that murder is also an instance of other wrongdoings. For example, murder is a necessary part of mass murder. So perhaps murder is graver as a result. Maybe...but there does seem to be some important differences. For murders are not predominantly instances of mass-murders; whereas, conceivably, rapes are predominately (or at least more often) acts of oppression. Likewise, although undoubtedly murder affects some groups more than others, it seems rape is, and has been, to a far greater extent disproportionately enacted upon women.

These historical features allow us to explain an intuition, and answer a challenge, introduced by Luck (2009a). Namely, why it is that,

...although computer games which entail virtual murder may be socially acceptable, it is doubtful that a game involving, for example, only murdering Jews or homosexuals, would be tolerated. It seems therefore, that unfairly singling out a group for harm is, in itself, additionally harmful. (Luck, p.34)

This additional harm is noticeable as the Jewish and gay communities have both been the victims of oppression, so unfairly singling them out for virtual murder makes the action graver still. In contrast, if the group singled out for harm were, for example, non-disabled people, we probably would not register any additional harm.

We might wish to consider further counter-examples at this juncture. For example, imagine a shooter game where you exclusively murder white Americans as a black American. ${ }^{23}$ Many people would presumably think playing such a game would be impermissible. But it couldn't be suggested that this is because of a history of black Americans oppressing white Americans. Yet, racially motivated attacks in general may be graver than their counterparts. Perhaps because there is a shameful history of racially motivated attacks. And this reason is compatible with further reasons: perhaps such attacks are also intrinsically worse (conceivably murdering someone because of their race, constitutes both murder and an instance of racism); or perhaps because the game heightens xenophobia in general, cultivating an usand-them mentality that feeds the view that "black people are threats". ${ }^{24}$

On this point I should be clear that, although some off-limits wrongdoings (e.g. molestation, rape, and homophobic and anti-Semitic aggression) may be graver than some fair-game wrongdoings (e.g. murder, stealing, and false imprisonment) as they are also instances of oppression, I am not suggesting they are graver only because they are instances of oppression (there may be additional reasons). Nor am I suggesting: that all off-limits wrongdoings are acts of oppression; that all grave wrongdoings are acts of oppression ${ }^{25}$; or that fair-game wrongdoings (such as murder) aren't grave (just that off-limit wrongdoings are graver still). My aim here is merely to illustrate one way that some off-limits wrongdoings may be graver than

\footnotetext{
${ }^{23}$ My thanks to a blind reviewer for this suggestion.

24 My thanks to a blind reviewer for this suggestion.

25 Although all acts of oppression are grave, it does not follow that all grave wrongdoings are acts of oppression. For example, intentionally causing a catastrophic bushfire is a grave wrongdoing (both serious and solemn), although it is not an act of oppression.
} 
fair-game wrongdoings because of their social context. But off-limits wrongdoings may be graver than fair-game wrongdoings for other reasons. That is, there may be other ways of affecting the graveness of a wrongdoing beyond it being, for example, an instance of oppression.

Another way of affecting the graveness of a wrongdoing may be to do with the passing of time; with the graveness of a wrongdoing decreasing over time. This might help explain the too soon phenomenon in comedy, where some jokes should not be told too soon after the tragic events to which they refer. Perhaps this is because some events are too grave at the time of their occurrence (and for some time afterwards) to treat lightly. And so, by telling a joke about an event too close to its occurrence, one is doing something wrong (like being insensitive or disrespectful). This might explain why virtually murdering people in a computer game as Peter Niers (a German bandit who died in 1581 and reputedly killed over 500 people) might seem less wrong than virtually murdering people as Stephen Paddock (the Las Vegas gunman who killed over 50 people in 2017).

Likewise, perhaps the graveness of a wrongdoing decreases as it is distanced from reality. ${ }^{26}$ For example, a computer game that allows you to play the fictional alien over-lord Zlarg, whose aim is to wipe out other alien races, might be more permissible than a game which allows you to play the fictional German Fuhrer Padolf Pitler, whose aim is to wipe out the Jewish people. Perhaps this is (at least partly) because sometimes the graveness of a fictional wrongdoing increases the more similar it is to a real instance of a wrongdoing. We might call this the too close phenomenon, to mirror the too soon phenomenon. ${ }^{27}$

Furthermore, the graveness of a wrongdoing may depend on who commits it. Kieran gives us an example of this regarding jokes:

We might laugh at or gasp in horror at the same joke depending upon who's telling it and why. Take a joke that relies on assuming the fecklessness of black

\footnotetext{
26 Patridge makes the same point in respect to incorrigible social meaning.

27 And there may be empirical support for both the too soon and too close phenomena. For example, regarding jokes about tragedies, McGraw et al. (2014) found that the passing of time "creates a comedic sweet spot that occurs when the psychological distance from a tragedy is large enough to buffer people from threat (creating a benign violation)..." (p.566). Likewise, a study by Cesarei and Codispoti (2008) suggested the smaller and lower the resolution of an image, the less-pronounced our emotions about the image would be. They note evidence that: "

The largest activation [of emotional responses] follows real world stimuli that contain the largest number of descriptive features, for example, feeling the contact with a real poisonous [sic] snake. In comparison, progressively impoverished versions of the same stimulus that only preserve some of the original features (e.g., a picture or a drawing depicting a snake) would be less effective in activating nodes of associative networks and, therefore, would result in less-pronounced emotional responses..."(p.360)

However, even if studies indicate that the greater the psychological distance (be it in time, or in closeness to the actual world) from something like a tragedy or a venomous snake, the less likely it is to elicit a pronounced negative response (such as a feeling of graveness), this may not get us too far. For although evidence of such intuitions is a helpful start, what we are looking for a moral justification for the intuition that we should permit one type of action, but not another. We are not looking for a psychological explanation for the intuition that one type of action is permissible, but not another. The projects are distinct (unless one is an ethical naturalist).
} 
men. If Chris Rock tells the joke we might laugh but if someone from the $\mathrm{Ku}$ Klux Klan tells it we might be appalled.(p.142)

A further example, provided by Davnall (2018), is that of people playing GTA; a game that arguably represents "working class people of colour as violent"(p.7).

There may be reappropriative ways for black people to engage with Grand Theft Auto games, analogous with the reappropriation of slurs...Any white person engaging with these games, though, must be subject to careful scrutiny for the ways in which they contribute to the symbolic reinforcement of racism and class. (p.5)

Davnall's example helps us to see the possibility that the same act (in this case playing GTA) might be graver when performed by white people. As "a white person playing the game participates in a representation that has historically been used by white people to justify racial discrimination against people of colour"(p.7). In other words, participating in the misrepresentation of people based on their race might be a grave wrongdoing, but it graver still when undertaken by groups that have a long history of systemically benefiting from such acts.

So, to summarize, graveness is sensitive to a number of factors. A wrongdoing might be graver: the more it entails further wrongdoings (like rape being both a sexual attack and an instance of oppression, or a racially motivated murder being both a lethal physical attack and an instance of racism); the more recently it has occurred (like the recent exploits of Stephen Paddock being graver than Peter Niers); the closer it is to an real instance of a wrongdoing (like a game where you play the fictional German Fuhrer Padolf Pitler); if committed by people who have systemically benefited from such a wrongdoing (like the misrepresentation of black people by white people). And there will be further factors than these. The point here is to suggest that the graveness of a wrongdoing can be affected by such factors; factors that we may not notice when wrongdoings are "abstracted from their natural context"(Öhman, 2020, p.133). And once a wrongdoing is sufficiently grave it may become off-limits.

And why is it that treating off-limits wrongdoings lightly is wrong? I am attracted to an explanation from virtue ethics, as is McCormick (2001), Corvino (2002), and Patridge (2013). Corvino offers a theory that might be adapted to explain why treating off-limits wrongdoings lightly is wrong; for treating off-limits wrongdoings lightly involves possessing an attitude to the wrongdoing which is incompatible with a proper appreciation of its graveness. Thus, the action demonstrates a failing of character. ${ }^{28}$ And so, as Partridge suggests, anyone who treats off-limits wrongdoings

\footnotetext{
28 This may correspond to how we actually may make moral judgments. Sabo and Giner-Sorolla's (2017) experiments identified that fictional purity violations (such as virtual child molestation) are evaluated more negatively than fictional acts that are harmful, but are not purity violations (such as virtual murder), as they are "seen as more diagnostic of bad character" (p.134). (However, we should be wary not to confuse is with ought here.)
} 
lightly therefore exposes a flaw in their character (p.312). Which we might register as being disrespectful, ignorant, insensitive, cavalier, or offensive etc. ${ }^{29}$

The aim here has been to provide reason to think that, although one wrongdoing might not be obviously graver than another when we only consider the nature of the wrongdoing itself, it might be graver once we consider other factors (such as: the extent that a wrongdoing is part of another; how long ago the wrongdoing occurred; how similar is it to an real instance of a wrongdoing; and who performed the wrongdoing). And it is because of such factors that off-limits wrongdoings may be graver than fair-game wrongdoings all things considered. And if off-limits wrongdoings are graver, then it is possible they may be too grave to make light of, whereas fair-game wrongdoings might not.

These points are being made in order to support the following argument:

9. Fair-game wrongdoings are not too grave, and off-limits wrongdoings are too grave.

10. Treating a wrongdoing lightly is permissible only if the wrongdoing is not too grave.

So,

11. Fair-game wrongdoings have some property off-limits wrongdoings lack, where treating such wrongdoing lightly is permissible only if they have this property.

Where if this conclusion is true, proposition 2 of the paradox of treating wrongdoing lightly will be false. Which would resolve this paradox and in turn resolve the gamer's dilemma.

\footnotetext{
${ }^{29}$ There have also recently been two worthwhile attempts at providing a Kantian account of the wrongness of virtual murder. However, I am less sure these attempts could be modified to explain the wrongness of treating fictional wrongdoings lightly. For example, Tilson (2018) argues that virtual/simulated murder is always to some extent wrong "by virtue of constituting a disrespectful act" (p.206) - but deliberately does not extend his argument the mere representation of a wrongdoing. Likewise Flattery (2021) argues that some instances of virtual murder may occur where the player "might employ maxims that would fail to satisfy the Categorical Imperative" - but these instance relate to cases where we "find ourselves mistaking — or being led to mistake - the virtual for the real" (p.10). Alternatively Milne \& Ivankovic (2021) provide a potential consequentialist resolution to the gamer's dilemma, arguing that "the taboo against paedophilia not only exists, unlike any taboo against murder, but also seems more easily justifiable on a rule-consequentalist basis" (p.15). This account I think could more easily be adapted to explain the wrongness of treating fictional wrongdoings lightly. As doing so in cases of off-limit wrongdoings may be taboo, and these taboos (as a rule) protect us from harm (it might be argued).
} 


\section{The Gamer's Dilemma Again}

To bring this all home, let us briefly return to the gamer's dilemma. The central idea here is that some cases of virtual murder (X cases) represent fair-game wrongdoings (e.g. driving over an innocent bystander in the game GTA). And some cases of virtual child molestation (Y cases) represent off-limits wrongdoings (e.g. molesting a child in the game Rapelay). These are the cases where the dilemma seems to hold. ${ }^{30}$ When comparing such cases we find there is a relevant difference. Namely that child molestation is graver than murder. How much graver? It's hard to know exactly. But in these cases it seems child molestation is grave enough that, by engaging with it representation in a carefree or light-hearted manner, we treat it too lightly - whilst the same is not true of murder. So, what we now hopefully have is a principled way to draw a line.

Of course just because we have a principled line, doesn't mean it will always be easy to draw it. However, this is a more general problem - and the grave resolution is in good company here. For example, utilitarianism is a clear and principled way to distinguish between actions that result in the most overall utility (which we should perform), and those that don't (which we shouldn't). But although the principle is clear, this doesn't mean that it is always easy to apply. There will be cases where is will be very hard to determine which action will result in the most overall utility. Likewise, although I have outlined different factors that may affect the graveness of an action - which may aid us in the drawing of such a line, there will be cases where is will be hard to determine whether a wrongdoing is indeed too grave to make light of. (Perhaps future work might reduce such grey areas.)

\section{Conclusion}

The aim of this paper was to present a more explicit formulation of the gamer's dilemma, and to illustrate how a potential resolution to this dilemma, the grave resolution, might also resolve a wider set of analogous dilemmas. To this end the dilemma was expressed as a paradox, limited to fair-game wrongdoings and off-limit wrongdoings, and widened in scope (so it applied more broadly to cases where such wrongdoings are treated lightly). The property of graveness was then introduced, and some reason given for why the degree of graveness might, at least partly, be

\footnotetext{
${ }^{30}$ It is worth noting that, following Ali (2015), there may be cases of virtual murder that are off-limits (e.g. in a baby murder simulation game), and cases of virtual child molestation that are fair-game (e.g. in a story game where the narrative makes it clear the act should not be treated lightly). So, we cannot assume all cases of virtual child molestation are graver than all cases of virtual murder. And in cases where the graveness of such acts are the same, the gamer's dilemma will not hold (which is perhaps another way of framing Ali's central thesis). But this possibility still allows for the dilemma to hold in cases where the graveness of virtual child molestation is sufficiently graver than that of virtual murder. And, somewhat contrary to Ali, the grave resolution doesn't necessitate that virtual impermissible acts that have similar in-game contexts will also have similar levels of graveness (although it doesn't exclude the possibility either).
} 
determined by extrinsic and contingent factors (in addition to intrinsic and necessary factors). This was done in an effort to explain both, (a) why some wrongdoings which seem equally intrinsically grave, may not be all-thing-considered equally grave, and (b) why it may be permissible to make light of some wrongdoings and not others, as some wrongdoings may be too grave to make light of. Of course, we should leave open the possibility that a single resolution might not successfully resolve the paradox of treating wrongdoing lightly. There might be multiple resolutions that together resolve the paradox. However, the first step is to establish such resolutions (be they singular or multiple) to see if they actually do the work they should. The next step will be to compare them. ${ }^{31}$

\section{Declarations}

Conflict of Interest The authors declare that they have no conflict of interest.

The authors did not receive support from any organization for the submitted work.

\section{References}

Ali, R. (2015). A new solution to the gamer's dilemma. Ethics and Information Technology, 17, $267-274$. Bartel, C. (2012). Resolving the gamer's dilemma. Ethics and Information Technology, 14(1), 11-16.

Bartel, C. (2020). Video games, violence, and the ethics of fantasy: Killing time. New York City.

Bethesda Game Studios. (2016). The Elder Scrolls V: Skyrim. Digital game directed by Todd Howard, published by Bethesda Softworks.

Corvino, J. (2002). Naughty fantasies. Southwest Philosophy Review, 18(1), 213-220.

Davnall, R. (2018). Grand theft argument: The problem with paradigm cases of virtual violence. The Philosophy of Computer Games Conference.

Davnall, R. (2020) What does the gamer do? Ethics and Information Technology. https://doi.org/10. 1007/s10676-020-09558-8

De Cesarei, A., \& Codispoti, M. (2008). Fuzzy picture processing: Effects of size reduction and blurring on emotional processing. Emotion, 8(3), 352-363.

Flattery, T. (2021). May Kantians commit virtual killings that affect no other persons?. Ethics and Information Technology. https://doi.org/10.1007/s10676-021-09612-z

Heinrichs, J. H. (2020) Virtual action. Ethics and Information Technology. https://doi.org/10.1007/ s10676-020-09574-8

Kieran, M. (2006). Art, morality and ethics: On the (Im) moral character of art works and inter-relations to artistic value. Philosophy Compass, 1, 129-143.

Kjeldgaard-Christiansen, J. (2020). Splintering the gamer's dilemma: Moral intuitions, motivational assumptions, and action prototypes. Ethics and Information Technology, 22, 93-102.

Luck, M. (2009a). The gamer's dilemma: An analysis of the arguments for the moral distinction between virtual murder and virtual paedophilia. Ethics and Information Technology, 11(1), 31-36.

Luck, M. (2009b). Crashing a virtual funeral: Morality in MMORPGs. Journal of Information, Communication \& Ethics in Society, 7(4), 280-285.

Luck, M., \& Ellerby, N. (2013). Has Bartel resolved the gamer's dilemma? Ethics and Information Technology, 15(3), 229-233.

Luck, M. (2017). Formulating the Gamer's dilemma. Video games and virtual ethics [keynote address 21 July] (London: The Open University \& the Institute of Philosophy).

\footnotetext{
31 My thanks to Rami El Ali, Christopher Bartel, Wylie Breckenridge, Daniel Cohen, Ryan Dennison, Hayley Gifford, Stephanie Patridge, Emma Rush, John Tilson, Suzanne Uniacke, \& Garry Young.
} 
Luck, M. (2018). Has Ali dissolved the gamer's dilemma? Ethics and Information Technology, 20, 157-162.

Maxis. (2000). The Sims. Digital game published by electronic arts.

McCormick, M. (2001). Is it wrong to play violent video games? Ethics and Information Technology, $3(4), 277-287$.

McGraw, A. P., Williams, L. E., \& Warren, C. (2014). The rise and fall of humor: Psychological distance modulates humorous responses to tragedy. Social Psychological and Personality Science, 5(5), $566-572$.

Mildenberger, C. (2017). Virtual killing. Philosophical Studies, 174(1), 185-120.

Milne, O. Ivankovic, V. (2021). Computer game design and moral engagement. In play, philosophy and performance, MacLean, M., Russell, W., \& Ryall, E. (Eds.) Routledge

Nader, K. (2020). Virtual competitions and the Gamer's Gilemma. Ethics and Information Technology, $22,239-245$

Nguyen, C. T. (2017). Philosophy of games. Philosophy Compass., 12, e12426. https://doi.org/10.1111/ phc3.12426

Öhman, C. (2020). Introducing the pervert's dilemma: A contribution to the critique of Deepfake pornography. Ethics and Information Technology, 22, 133-140. https://doi.org/10.1007/ s10676-019-09522-1

Patridge, S. (2013). Pornography, ethics and video games. Ethics and Information Technology, 15, 25-34.

Ramirez, E. J. (2020). How to (dis)solve the Gamer's dilemma. Ethical Theory and Moral Practice, 23, $141-161$.

Sabo, J. S., \& Giner-Sorolla, R. (2017). Imagining wrong: Fictitious contexts mitigate condemnation of harm more than impurity. Journal of Experimental Psychology, 146(1), 134-153.

Sainsbury, R. M. (2009). Paradoxes. Cambridge.

Seddon, R. F. J. (2013). Getting 'virtual' wrongs right. Ethics and Information Technology, 15, 1-11.

Tilson, J. (2018). Is it distinctively wrong to simulate doing wrong? Ethics and Information Technology, $20,205-217$.

Young, G. (2016). Resolving the Gamer's dilemma: Examining the moral and psychological differences between virtual murder and virtual Paedophilia. Cham.

Young, G. (2019). An expressivist account of the difference between poor taste and immorality. Ethical Theory and Moral Practice, 22, 465-482.

Young, G. (2021). Fictional immorality and immoral fiction. New York City.

Publisher's Note Springer Nature remains neutral with regard to jurisdictional claims in published maps and institutional affiliations. 